\title{
Scoliosis: a rare manifestation of intrinsic tumours of the spinal cord in children
}

\author{
M. BANNA, G. W. PEARCE, AND R. ULDALL
}

From the Regional Neurological Centre, Newcastle General Hospital and the University of Newcastle upon Tyne

SUMMARY Three cases are described of apparent idiopathic scoliosis in childhood which were shown subsequently to be due to intramedullary spinal cord tumour. The possibility of this underlying lesion should be considered in any child who develops scoliosis without an obvious cause.

When scoliosis is first diagnosed during childhood, it commonly falls into one of three categories; congenital, paralytic, or idiopathic. The congenital variety is due to vertebral malformation present since birth. The paralytic type will be recognizable by the presence of obvious preceding neurological disease. Idiopathic scoliosis, on the other hand, must remain a diagnosis of exclusion. It would appear that when scoliosis is the main presenting feature in a case of spinal cord tumour, the cause of scoliosis is inclined to be overlooked.

The purpose of this communication is to descrite three cases of spinal cord neoplasm which were concealed by scoliosis. In the first case the tumour was discovered only at necropsy, while in the other two cases the correct diagnoses were made after long periods of unsuccessful medical and surgical treatment of the deformity. The myelographic appearances in cases 2 and 3 have appeared in a previous publication (Banna and Gryspeerdt, 1971).

\section{CASE 1}

F.R. (Fig. 1). A 36 year old man was admitted to Newcastle General Hospital on 15 January 1970. Despite a history of paraplegia since the age of 12 , he had managed to earn a living as a watchmaker and was happily married leading a wheel-chair existence, largely independent of help. The original cause of the patient's paraplegia had been quoted as 'curvature of the spine and Friedreich's ataxia'. Hospital records relating to this diagnosis were unavailable. For many years he had suffered from bed sores. His right leg had been amputated.

Three weeks before admission the patient noticed increasing oedema of the legs, thighs, abdomen, chest, and arms. While previously his urine output was good with automatic emptying of the bladder, he was now oliguric.

Examination revealed an intelligent and cooperative young man with generalized pitting oedema of the dependent parts and some ascites. There was gross scoliosis of the dorsolumbar spine and a huge suppurating pressure sore involving sacrum and buttocks. He was totally paralysed and anaesthetic below waist level. His urine contained protein to the extent of $10 \mathrm{~g}$ in 24 hours and was heavily infected.

He was treated intensively with diuretics and intravenous albumin with a good response initially. It was proposed to carry out a renal biopsy, but increasing uraemia made this impossible and peritoneal dialysis was required. This treatment was successful for a few days, but he then developed peritonitis and septicaemia. In spite of vigorous antibiotic therapy, he died less than two weeks after his admission to hospital.

NECROPSY FINDINGS Severe kyphoscoliosis was found together with a glial tumour occupying the lumbosacral region of the spinal cord. The cause of death was peritonitis together with uraemia associated with a markedly severe amyloid nephropathy confirmed by histology (haematoxylin and eosin, crystal violet, congo red and thioflavine $\mathbf{T}$ fluorescence).

The lumbosacral and lower two thoracic segments of the spinal cord were replaced and diffusely enlarged by an intramedullary tumour (Fig. 1a). The remainder of the thoracic cord was grossly reduced in its anteroposterior diameter acquiring a ribbon-like shape. The cervical cord was also thin but to a lesser extent. Sections of the tumour showed a firm mass with some necrosis and cyst formation. Above the tumour the thoracic cord showed a syringomyelic cavity surrounded by a thick wall of gliosis which occupied approximately the central two thirds of the cord with the remainder of the cord peripherally showing almost complete loss of neural tissue. The size of the central cavity was not uniform and varied from segment to segment. The cervical cord was only slightly reduced in size and showed a smaller cavity surrounded by a gliosed wall but with preservation of neural tissue peripherally. The attenuated syringomyelic cavity continued rostrally into the closed part of the medulla and opened at the surface of the fourth ventricle, $3 \mathrm{~mm}$ 


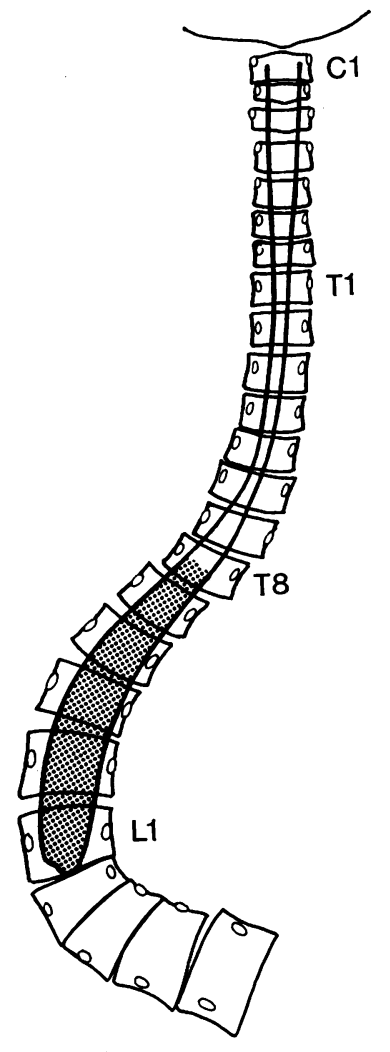

FIG. 1a. Case 1 . Diagram based on survey radiographs and necropsy findings depicting the degree of scoliosis and the size of the intramedullary tumour (stippled area).

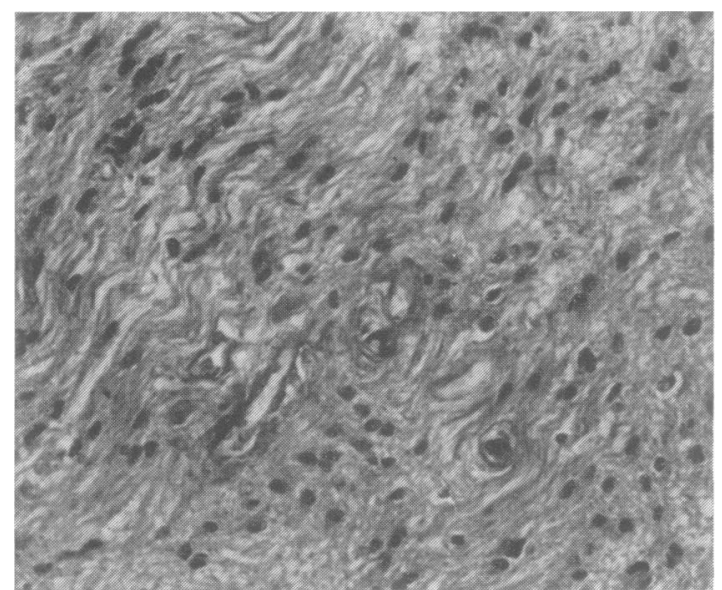

FIG. 1b. Case 1. Histology of the tumour: highly fibrillary and poorly cellular astrocytoma. Masson trichrome stain, $\times 250$.

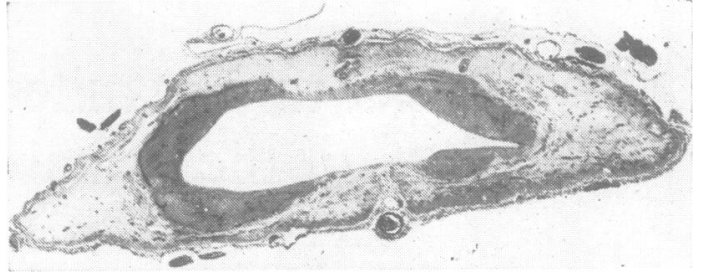

FIG. 1c. Case 1. Section of the thoracic spinal cord showing syringomyelic cavity, largely surrounded by $a$ dense zone of gliosis with peripheral loss of neural tissue. Masson trichrome stain, $\times 15$.

above the obex. There was no other abnormality of the brain-stem or cerebellum. Multiple coronal brain sections showed no abnormality other than slight oedema with reduction in size of the sulci. The region of the foramen of Magendie was normal.

NEUROHISTOLOGY Sections through the tumour (Fig. 1b) showed a poorly cellular and fibrillary astrocytoma with a number of large hyalinized astrocytes of which a small number contained two or rarely more nuclei. Rosenthalö fibres were seen and a little calcification was evident in $\mathbb{D}$ one part. There were no mitotic figures. Vessels were $\frac{O}{\mathbb{D}}$ prominent with thickened collagenous walls and an area of dense hyalinized connective tissue was also present Sections through the thoracic spinal cord rostral to the tumour confirmed the naked eye appearances of a centralo cavity surrounded by a gliosed collar with loss of neural tissue peripherally (Fig. 1c). The spinal cord itself was surrounded by a layer of dense proliferated connective tissue which enclosed the anterior spinal vessels. The junction between thoracic and cervical segments was relatively abrupt. Neural tissue, both tracts and neurones, was largely preserved in the cervical regions as were remnants of the central canal ependymal cells behind which was found the small syringomyelic cavity surrounded by a dense glial ring. Amyloid was not demonstrated in any part of the tumour, spinal cord or brain.

\section{CASE 2}

K.J.D. (Fig. 2). A boy aged 13 years was admitted in July 1965 , with a long history of back pain and scoliosis for which he had received traction treatment without any benefit. In January 1966, fusion of the lower lumbar spine was performed. Two months later, when the plaster was removed it was noticed that he had extreme weakness of both lower limbs. This got progressively worse. Neurological advice was sought and on admission to the Neurological Centre he had severe weakness of all four limbs with bilateral foot-drop, flaccid paresis, and absent reflexes. Lumbar puncture revealed cerebrospinal fluid (CSF) protein of $4,150 \mathrm{mg} / 100 \mathrm{ml}$. Lumbar and cisternalroute myelograms were performed to show the extent of the expanded cord (Fig. 2a). At operation, a total laminectomy of T8 to L1 inclusive was carried out. The tumour 


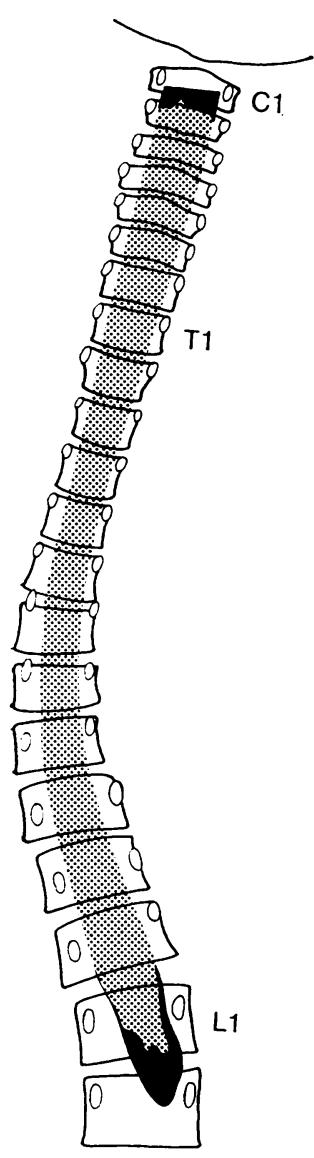

FIG. 2a Case 2. Diagram based on myelography (Myodil in solid black), depicting the degree of scoliosis and the length of the dilated segments of the spinal cord (stippled area).

was explored and was found to be solid in its upper part but its lower part was cystic. The protein content of the fluid aspirated from the cyst was $4.6 \mathrm{~g} / 100 \mathrm{ml}$. Histological examination of the biopsy obtained from the solid part of the tumour showed a well-differentiated and poorly cellular astrocytic glioma (Fig. 2b).

CASE 3

P.M. (Fig. 3). A boy aged 8 years was admitted to another hospital in 1963 having suffered from neck stiffness over the past six years, for which he received several forms of medical treatment elsewhere. On examination he had limitation of movement of his neck and scoliosis of the dorsal spine. The only neurological signs found at that time were a diminished left knee jerk and absent ankle jerks. Lumbar puncture revealed a CSF protein of $240 \mathrm{mg} / 100 \mathrm{ml}$. A lumbar-route myelogram was performed and showed complete obstruction at T12 vertebral level. The lesion was explored and an intramedullary partially cystic swelling was found. A high protein containing fluid was obtained from the cyst.

In May 1965, the child was admitted to the Regional

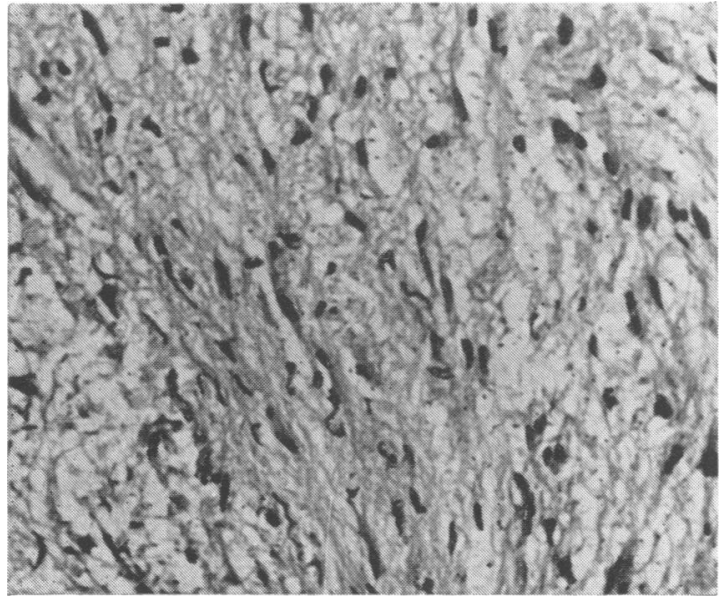

FIG. 2b. Case 2. Histology of the tumour biopsy: poorly cellular fibrillary astrocytoma. $H$ and $E, \times 250$.

Neurological Centre with physical signs suggesting involvement of the cervical part of the spinal cord. The upper limit of the expanded cord was outlined by Myodil introduced via the lateral ventricle. (Fig. 3a.) The cervical part of the lesion was decompressed. Biopsy showed a poorly cellular fibrillary astrocytoma (Fig. 3b).

\section{DISCUSSION}

The various causes of scoliosis are well known (Roaf, 1966). In some patients it is associated with, but not necessarily caused by, a neuromuscular disorder such as muscular dystrophy, dystonia, poliomyelitis, Friedreich's ataxia, syringomyelia, or neurofibromatosis (Thomas, 1968). There are, however, a few cases in which the neurological deficit is a direct result of the scoliosis (McKenzie and Dewar, 1949). In these the deformity is usually severe, involving the thoracic region, and affecting the spinal cord. Kleinberg (1951) summarized the pathological conditions which may lead to paraplegia in cases of scoliosis as follows: (1) marked kyphosis; (2) tightness of the dura mater; (3) bony spurring of the neural canal; (4) extradural anomalous pressure band; (5) osseous ridge at the apex of the curve in front of the spinal cord; (6) acute angulation of the cord.

Scoliosis due to intramedullary spinal cord tumours is extremely rare. Few reports have been found in the literature (Boldrey, Adams, and Brown, 1949; Williams and Stevens, 1953) and in these many of the lesions were non-neoplastic. In spite of its rarity, the association of scoliosis with tumours of the spinal cord is important for many reasons. If the 


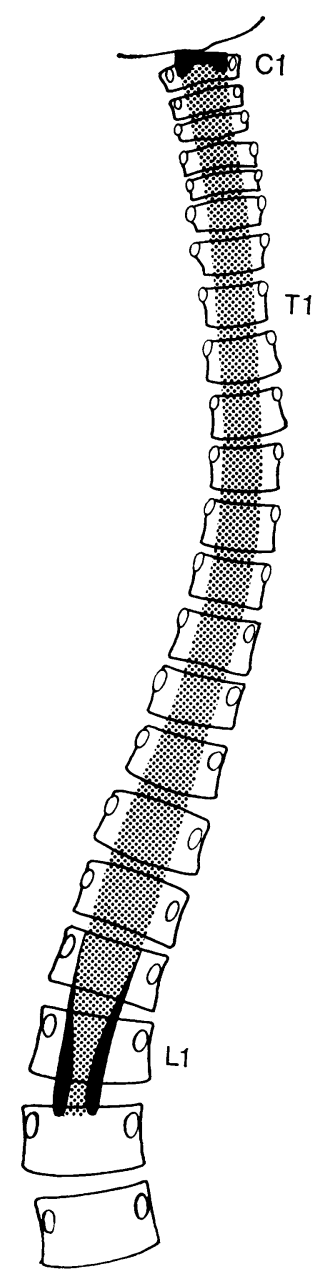

FIG. 3a. Case 3. Diagram based on myelography (Myodil in solid black), depicting the degree of scoliosis and the extension of the widened spinal cord (stippled area). neurological deficit is slight, the children are too often thought to suffer from idiopathic scoliosis and treated accordingly. This is more liable to occur because they are often of the same age group as the majority of children suffering from idiopathic scoliosis; 8 to 14 years old. Corrective treatment of the scoliosis may be harmful to the child. If, on the other hand, the child presents with an advanced neurological deficit, the possibility of a spinal cord tumour may not be considered. This is due to the fact that spinal cord tumours in children are rare, and difficult to diagnose. Their clinical presentation may simulate several other diseases which occur with greater frequency in childhood (Matson and Tachdjian, 1963). Furthermore, the changes in the pedicles, which they may produce, are often obscured

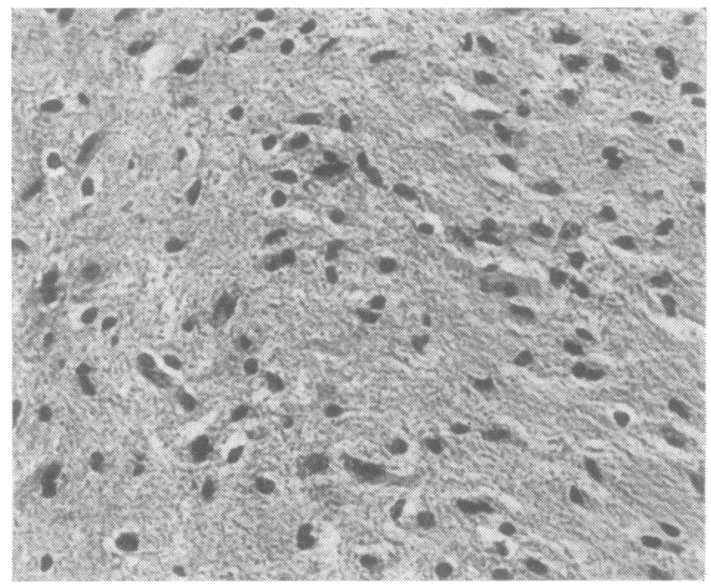

FIG. 3b. Case 3. Histology of the tumour biopsy: poorly cellular fibrillary astrocytoma. Haematoxylin and eosin stain, $\times 250$.

on the survey radiographs in the presence of scoliosis.

The spinal cord tumours which tend to cause scoliosis are usually relatively benign or of low $\frac{9}{\varnothing}$ 을 grade malignancy. They may be partly cystic, and $\stackrel{-}{-}$ may be associated with a large syringomyelic cavity. The latter may occupy many segments of the cord 8 웅 above a comparatively small tumour, which is suit-응 able for surgery or radiotherapy at least in its early stages. The distinction between solid and cystic $\vec{f}$ expansion of the cord in these cases is not possible on myelography.

As a general rule, the basic cause of paralytic scoliosis is muscular imbalance resulting in asymmetrical weakness of the trunk muscles. When the muscles on one side are weak, the corresponding muscles on the opposite side, being unopposed, begin to function too strongly, pulling a segment of the spine out of line. The direction of the curve produced, depends on the muscles involved. Weakness of one group of muscles seems unlikely to be the only mechanism leading to scoliosis in neurological diseases. Kleinberg (1951) suggested that it may possibly be due to disturbance of the nerve supply and nutrition of the vertebral body or epiphyseal plates. In cases of spinal cord tumours, pain and spinal rigidity are, perhaps, partly responsible for the scoliosis. Pain was present in our second and third cases at a time when no muscular weakness was apparent. Both backache and spinal rigidity are important clinical features of spinal cord neoplasm in children (Richardson, 1960).

From our cases and others previously described (Boldrey et al., 1949; Williams and Stevens, 1953; 
Matson and Tachdjian, 1963), it is evident that a number of children suffering from spinal cord lesions present with scoliosis. The deformity is often associated with backache and spinal rigidity. In many instances, the clinical examination and the survey radiographs are insufficient to reveal the true nature of the disease. Inevitably, several cases may be misdiagnosed. It seems appropriate, therefore, to suggest that, in the absence of an apparent cause of scoliosis in a child, a lumbar puncture should be performed and the CSF protein content estimated. While a normal finding is a reasonable assurance that scoliosis is not secondary to spinal cord neoplasm, a high protein content should be an indication for myelography to confirm or exclude the presence of an intraspinal neoplasm.

We wish to thank our colleagues, the paediatricians and neurosurgeons, for allowing access to the notes of cases 2 and 3.

We would also like to thank Mr. Michael Taylor for the histological work and photography.

\section{REFERENCES}

Banna, M., and Gryspeerdt, G. L. (1971). Intraspinal tumours in children (Excluding dysraphism). Clinical Radiol., 22, 17-32.

Boldrey, E., Adams, J. E., and Brown, H. A. (1949). Scoliosis as a manifestation of disease of the cervicothoracic portion of the spinal cord. Arch. Neurol. Psychiat. (Chic.), 61, 528-544.

Kleinberg, S. (1951). Scoliosis: Pathology, Etiology and Treatment. Baillière, Tindall, and Cox: London.

Matson, D. D., and Tachdjian, M. O. (1963). Intraspinal tumours in infants and children. Review of 115 cases. Postgrad. Med., 34, 279-285.

McKenzie, K. G., and Dewar, F. P. (1949). Scoliosis with paraplegia. J. Bone Jt Surg., 31-B, 162-174.

Richardson, F. L. (1960). A report of 16 tumors of the spinal cord in children; the importance of spinal rigidity as an early sign of disease. J. Pediat., 57, 42-54.

Roaf, R. (1966). Scoliosis, pp. 52-64. Livingstone: Edinburgh.

Thomas, P. K. (1968). The neuromuscular disorders in which scoliosis may occur. In Proceedings of a Second Symposium on Scoliosis: causation. pp. 46-49. London 1967. Edited by P. A. Zorab. Livingstone: Edinburgh.

Williams, J. M., and Stevens, H. (1953). Recognition of surgically treatable neurological disorders of childhood. J. Amer. med. Ass., 151, 455-458.

\section{The August 1971 Issue THE AUGUST 1971 ISSUE CONTAINS THE FOLLOWING PAPERS}

Focal dysplasia of the cerebral cortex in epilepsy D. C. TAYLOR, M. A. FALCONER, C. J. BRUTON, and J. A. N. CORSELLIS

Cervical spondylosis causing vertebrobasilar insufficiency: a surgical treatment DONALD R. SMITH, GARY D. VANDERARK, and LUDWIG G. KEMPE

The posterior operation in treatment of cervical spondylosis with myelopathy: a long-term follow-up study $\mathbf{s}$. N. BISHARA

An investigation of experimental myasthenia gravis $\mathbf{S}$. F. JONES, J. L. BRENNAN, and J. G. MCLEOD

Normal sensory conduction in the nerves of the leg in man FRIEDRICH BEHSE and FRITZ BUCHTHAL

Motor and sensory nerve conduction velocity in the baboon: normal values and changes during acrylamide neuropathy A. P. HOPKINS and R. W. GILLIATT

Clinical and pathological findings in an unusual infantile motor neurone disease RENATA KOHN

Cortisol in the cerebrospinal fluid of patients suffering from affective disorders ALEC COPPEN, B. W. L. BROOKSBANK, R. NOGUERA, and D. A. WILSON
Subdural spread of medulloblastoma: case report G. H. KOENIG

Incidence and distribution of neomembranes of dura mater REINHARD L. FRIEDE

Immunosuppressive therapy in polymyositis S. CURRIE and J. N. WALTON

Functional compensation in partially denervated muscles A. J. MCCOMAS, R. E. P. SICA, M. J. CAMPBELL, and A. R. M. UPTON

An electrophysiological study of Duchenne dystrophy A. J. MCCOMAS, R. E. P. SICA, and S. CURRIE

An electrophysiological investigation of limb-girdle and facioscapulohumeral dystrophy R. E. P. SICA and A. J. MCCOMAS

Invasion of cranial nerves by salivary cylindroma: four cases treated by radiotherapy MICHAEL SWASH

Effect of carbon dioxide inhalation on the pattern of gaseous metabolism in ischaemic zones of the primate cortex LINDSAY SYMON, G. KHODADAD, and G. MONTOYA

Book reviews

Copies are still available from the PUBLISHING MANAGER BRITISH MEDICAL ASSOCIATION, TAVISTOCK SQUARE, LONDON, WC1H $9 \mathrm{JR}$, price $£ 1.50$ 